\title{
Biodegradable double-targeted PTX-mPEG-PLGA nanoparticles for ultrasound contrast enhanced imaging and antitumor therapy in vitro
}

\author{
Jing $\mathrm{Ma}^{1,2,3, *}$, Ming Shen ${ }^{4, *}$, Chang Song $\mathrm{Xu}^{5, *}$, Ying Sun ${ }^{4}$, You Rong Duan ${ }^{4}$, Lian \\ Fang $\mathrm{Du}^{2}$ \\ ${ }^{1}$ Department of Ultrasound, Songjiang Hospital Affiliated to The First People's Hospital of Shanghai Jiao tong University, \\ Shanghai 201600, China \\ ${ }^{2}$ Department of Ultrasound, Shanghai First People's Hospital Affiliated to Shanghai Jiao tong University School of Medicine, \\ Shanghai 200080, China \\ ${ }^{3}$ Department of Ultrasound, Shanghai East Hospital Affiliated to Tong ji University, Shanghai 200120, China \\ ${ }^{4}$ State Key Laboratory of Oncogenes and Related Genes, Shanghai Cancer Institute, Renji Hospital, School of Medicine, \\ Shanghai Jiao Tong University, Shanghai 200032, P. R. China \\ ${ }^{5}$ Huai'an First People's Hospital, Nanjing Medical University, Jiangsu 223001, China \\ *These authors have contributed equally to this work \\ Correspondence to: Lian Fang Du, email: du_lf@163.com \\ You Rong Duan, email: yrduan@shsci.org \\ Keywords: double-targeted, nanoparticles, antitumor, ultrasound contrast enhanced imaging, pancreatic cancer \\ Received: July 25, $2016 \quad$ Accepted: October 19, $2016 \quad$ Published: November 09, 2016
}

\section{ABSTRACT}

A porous-structure nano-scale ultrasound contrast agent (UCA) was made of monomethoxypoly (ethylene glycol)-poly (lactic-co-glycolic acid) (mPEG-PLGA), and modified by double-targeted antibody: anti-carcinoembryonic antigen (CEA) and anti-carbohydrate antigen 19-9 (CA19-9), as a double-targeted nanoparticles (NPs). Anti-tumor drug paclitaxel (PTX) was encapsulated in the double-targeted nanoparticles (NPs). The morphor and release curve were characterized. We verified a certain anticancer effect of PTX-NPs through cytotoxicity experiments. The cell uptake result showed much more NPs may be facilitated to ingress the cells or tissues with ultrasound (US) or ultrasound targeted microbubble destruction (UTMD) transient sonoporation in vitro. Ultrasound contrast-enhanced images in vitro and in vivo were investigated. Compared with SonoVue, the NPs prolonged imaging time in rabbit kidneys and tumor of nude mice, which make it possible to further enhance antitumor effects by extending retention time in the tumor region. The novel doubletargeted NPs with the function of ultrasound contrast enhanced imaging and antitumor therapy can be a promising way in clinic.

\section{INTRODUCTION}

As a kind of safe biodegradable organic polymeric material approved by the FDA for human medical use, poly (lactic-co-glycolic acid) modified with $\mathrm{mPEG}$ (mPEG-PLGA) has been used in drug delivery system [1]. CA19-9 and CEA are specific markers highly expressed on the surface of pancreatic carcinoma cells. Particularly, the CA19-9 is rarely expressed or detected in normal tissue cells $[2,3]$. We carried out some concerned experiments that the PTX-mPEG-PLGA NPs graft-modified by CA199 and CEA antibodies may specifically recognize and adhere to the surface of pancreatic cancer cells or tissues, sustained-release PTX to kill tumor cells or inhibition its multiply. Besides, as a good physical promoting way, US or UTMD may facilitate loading drugs and gene nanoparticles uptaken by goal cells or tissues, such as tumors, eyes, skeletal muscle, heart and bone marrow stem cells without apparent tissue damage, and enhance drug or gene release in situ [4-10]. Thereby, we performed relevant experiments and found that much more doubletargeted PTX-mPEG-PLGA NPs were transferred into pancreatic cancer cells or tissues with US or UTMD, compared with those without US. 
Although many researches on targeted drug-loaded NPs delivery for tumor therapy have been done [11-15], the study on US real-time monitoring at the same time of anti-tumor treatment was rarely been reported.

We prepared double-targeted PTX-mPEG-PLGA NPs with double emulsion method. The inner water phase was removed by lyophilization and got sphericals with porous structure which may provide a basis for the excellent US scatterings, these nanoparticles, as a kind of novel US nano-UCAs, compared with SonoVue that were widely used for the clinical assessment of various diseases, some similar good contrast enhanced imagines with double-targeted PTX-mPEG-PLGA NPs are showed in vitro and in vivo. Our aim is to introduce this novel double-targeted nano-UCA with the integration of ultrasound contrast enhanced imaging and therapy.

\section{RESULTS}

\section{Fabrication and characterization of double- targeted NPs}

In infrared spectrum of double-targeted NPs (Figure $1)$, there were the ester bond peak in PLGA $\left(1757 \mathrm{~cm}^{-1}\right)$, the amide bond peak in anti-CEA and anti-CA19-9 antibody $\left(1620 \mathrm{~cm}^{-1}\right)$ and the carbon-oxygen bond peak in $\mathrm{mPEG}$ $\left(1034 \mathrm{~cm}^{-1}\right)$. That proved the double-targeted NPs was made up of mPEG-PLGA modified by targeted-antibody (anti-CEA and anti-CA-19-9 antibody).

The peak and average size of double-targeted NPs were respectively $136.3 \pm 5.2 \mathrm{~nm}$ and $88.6 \pm 3.5 \mathrm{~nm}$ (Figure $2 \mathrm{~A})$. The zeta potential of the NPs was $-13.4 \pm 1.5 \mathrm{mv}$ (Figure 2B). Under light microscopy, a large quantities of microbubbles of SonoVue degassed aqueous were viewed, much more NPs were rarely seen, which may demonstrate that the size of this kind of novel NPs was much less than that of SonoVue microbubble (Figure 2B). The morphology of NPs viewed by TEM was spherical with excellent dispersion and no aggregation (Figure 2C).

The entrapment efficiency and loading drug efficiency of double-targeted NPs were separately $91.32 \pm 3.25 \%$ and $2.666 \pm 0.092 \%$. About $97.57 \%$ of PTX was released during 4 hours from PTX solution. Whereas the release from NPs was slow and sustained as about $40 \%$ of the total was released in 4 hours and about $97.83 \%$ of the total was completely released in 72 hours. The PTX release rates from NPs at PH 5.0, 6.5 , 7.4 condition were similar, which predicted the drug release rates in vivo were under no influence of $\mathrm{pH}$ (Figure 3 ). The properties of slow and sustained release made it possible for anti-cancer drug to keep effect continuously and efficiently.

\section{Optimal US or UTMD condition}

The maximum cell uptake efficiency was $39.67 \pm 2.45 \%$. The selected optimal UTMD condition was: power, $1 \mathrm{~W} / \mathrm{cm}^{2}$, exposure time, $60 \mathrm{sec}$, SonoVue volume ratio, 2:5. Under the same optimal US condition, the cell uptake efficiency at 2:5 SonoVue volume ratio was higher than the one at 1:5 ratio, more amplified cavitational effects may be a major cause. (Figure 4).

\section{Cell uptake}

Greater and stronger red fluorescence was observed in the cytoplasm of CFAPC-1 cell at $2 \mathrm{~h}$ incubation of the RhB double-targeted NPs than RhB-PLGA-mPEG NPs,

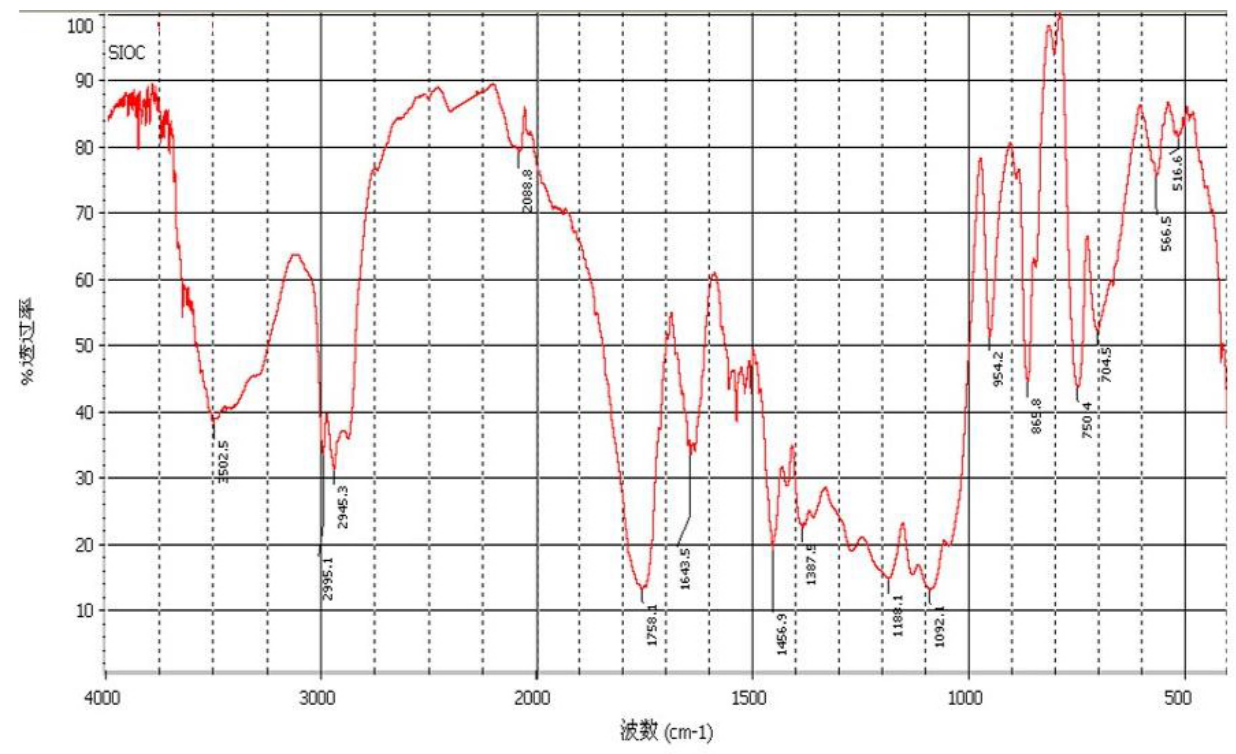

Figure 1: Infrared spectrum of double-targeted NPs. 

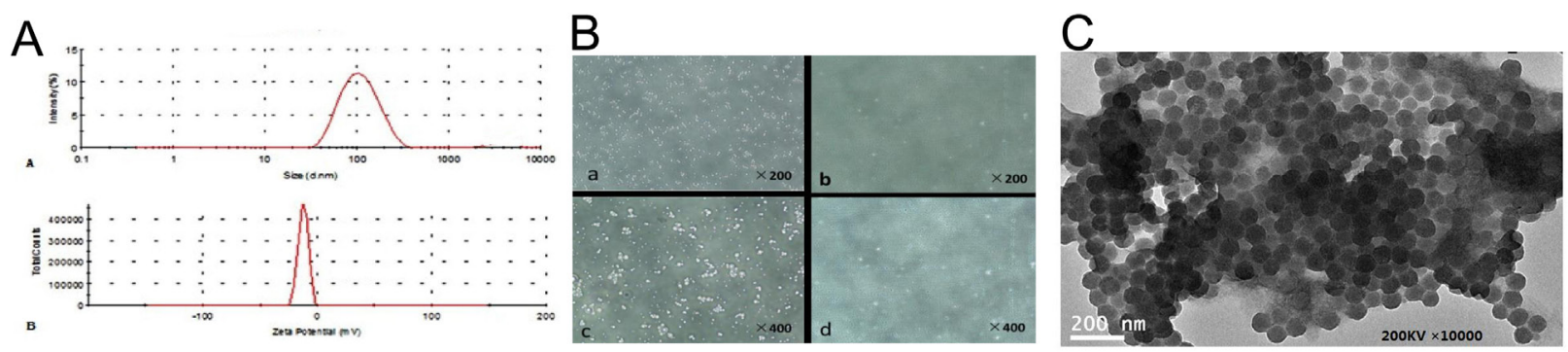

Figure 2: morphology of double-targeted NPs. A. Size distributions and zeta potential distribution of double-targeted NPs. B. SonoVue (a, c) and NPs (b, d) degassed aqueous observed by LM $(\times 200, \times 400)$. C. TEM of double-targeted NPs.

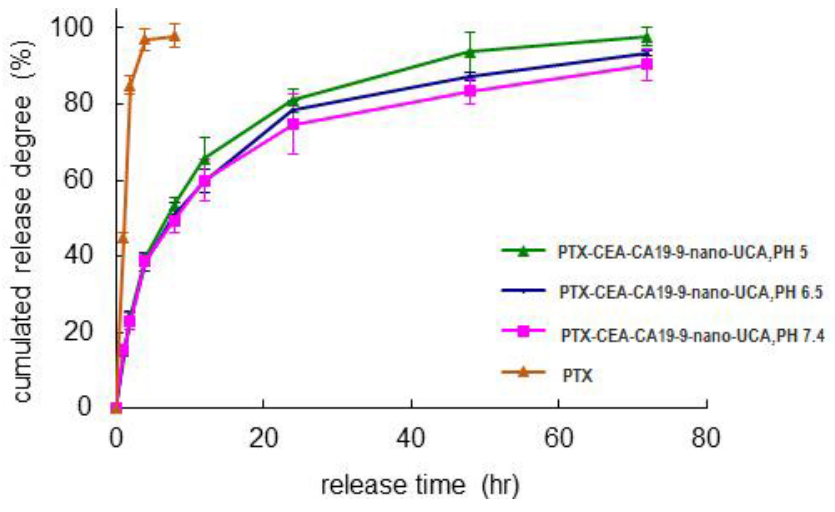

Figure 3: The PTX release from double-targeted NPs in different pH.

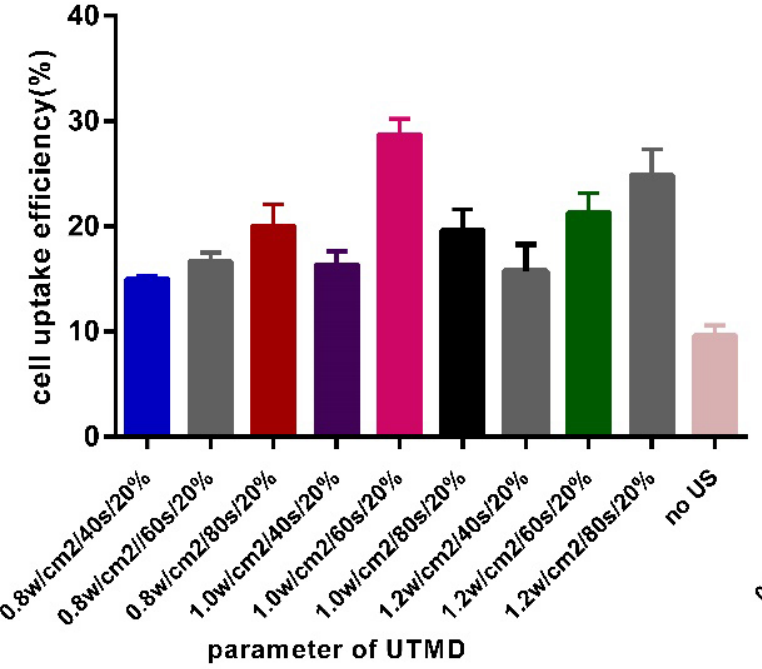

a

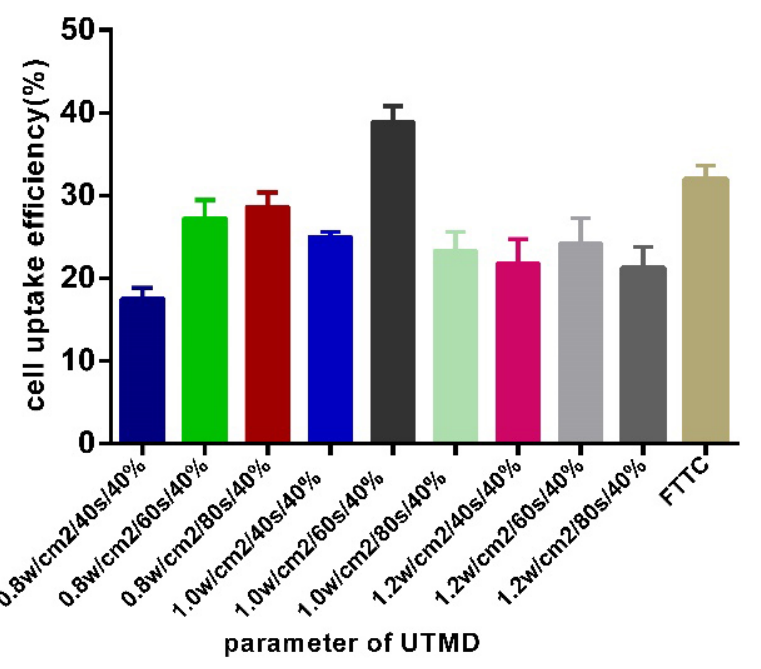

b

Figure 4: Optimal US or UTMD condition. 
which demonstrated good cell targeting of the doubletargeted NPs.

Much stronger fluorescence was respectively observed in CFAPC-1 cells under the administration of US than no US in both of the two NPs. Greater fluorescence was observed in CFAPC-1 cells under the administration of UTMD than US, which manifested US may facilitate much more NPs into cells, while UTMD have greater impact on cells than US (Figure 5). Red fluorescence was found in the cytoplasm of CFAPC-1 cell, not in the nucleus, which illustrated that it was possible for NPs to penetrate the gap of cell membrane but it was too difficult for them to penetrate the nuclear membrane to the inner of nuclear, even with US and UTMD.

\section{Cytotoxicity of double-targeted NPs}

The cell viabilities of AFPC-1 cells following administration of PBS, SonoVue, blank NPs, US, or UTMD for 24 or $48 \mathrm{~h}$ were all between 92 and $98 \%$ (Figure 6A). No significant differences in cell viability were identified between these groups $(p>0.05)$.

Under the Optimal US and UTMD conditions, it was possible for more targeted NPs to ingress the cells, guaranteeing the cytotoxic effect $(p<0.05)$. US and UTMD might promote NPs to enter the pancreatic cancer cells, more mechanisms might be unclear besides sonoporation. The efficiencies of US and UTMD to enhance NPs into pancreatic cancer cells were enhanced related to saturation of holes on the surface of cell membranes (Figure 6B, 6C).

\section{Two-dimensional ultrasonic imaging and ultrasound contrast enhanced imaging of UCAs in vitro}

Echoless was showed in the degassed aqueous neither in two-dimetional ultrasonic imaging nor in contrast enhanced imaging. NPs and SonoVue both showed dotted-like echoes in two-dimetional ultrasonic imaging and in contrast enhanced imaging. The difference was the dotted-like echoes of NPs were smaller than those of SonoVue (Figure 7).

\section{Two-dimensional ultrasonic imaging and ultrasound contrast enhanced imaging of UCAs in vivo}

Dynamic ultrasound contrast imaging process of rabbit kidney: To the kidney of rabbit, at the fifth second after vein bolus-injection, NPs began filling with starshaped, at the $24^{\text {th }}$ second reached to peak, last for six seconds, at the $30^{\text {th }}$ second, began pulling out quickly; at the $48^{\text {th }}$ second, began pulling out slowly, cleared up completely until 8 minutes. Correspondingly, at the $3^{\text {rd }}$ second after vein bolus-injection, SonoVue began filling rapidly, peaked at the $28^{\text {th }}$ second, lasted for 8 seconds, then faded swiftly, began fading slowly at $48^{\text {th }}$ second, until $5 \mathrm{~min}$, dissipated entirely. The SonoVue filling peak was higher than NPs, but the filling peak time of the nanoparticles was ahead of that of SonoVue, the pullingout time of NPs lasted for longer than SonoVue (Figure 8).

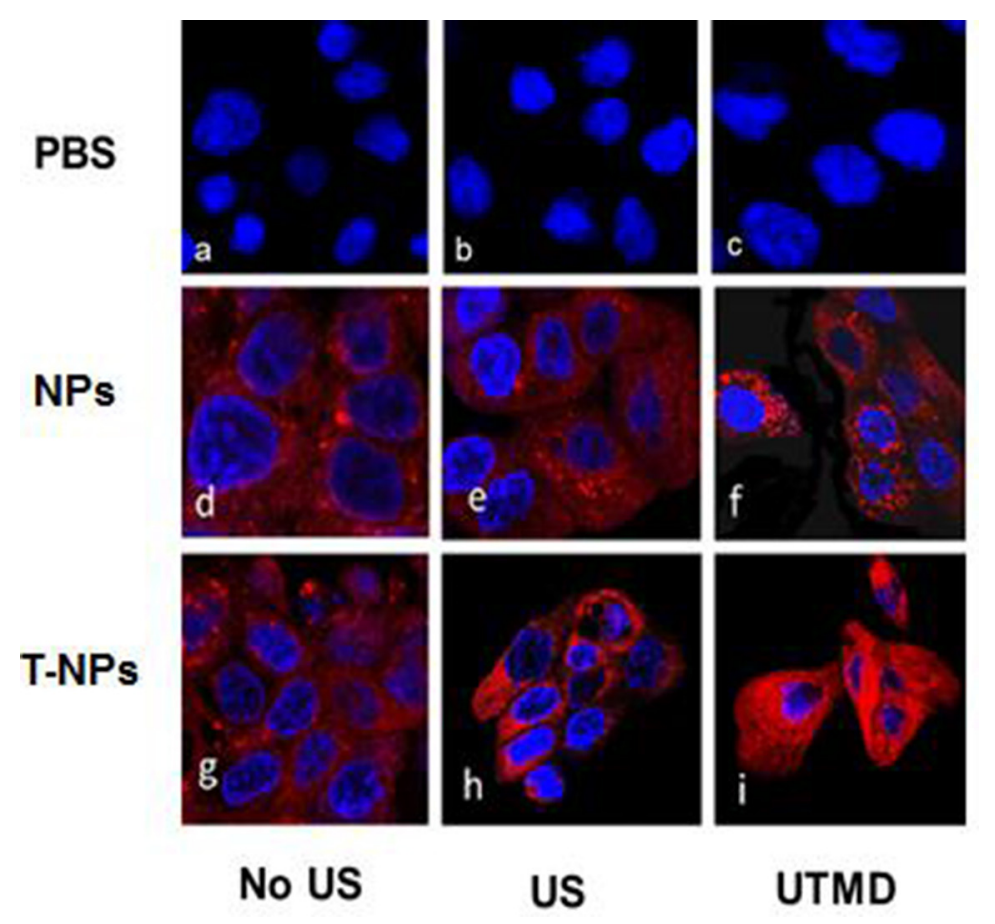

Figure 5: CLSM images of AFPC-1 cells after a $2 \mathrm{~h}$ incubation with the nanoparticles (NPs) with US or UTMD. DAPI were blue fluorescent nuclear staining and red fluorescence was from the RhB. 

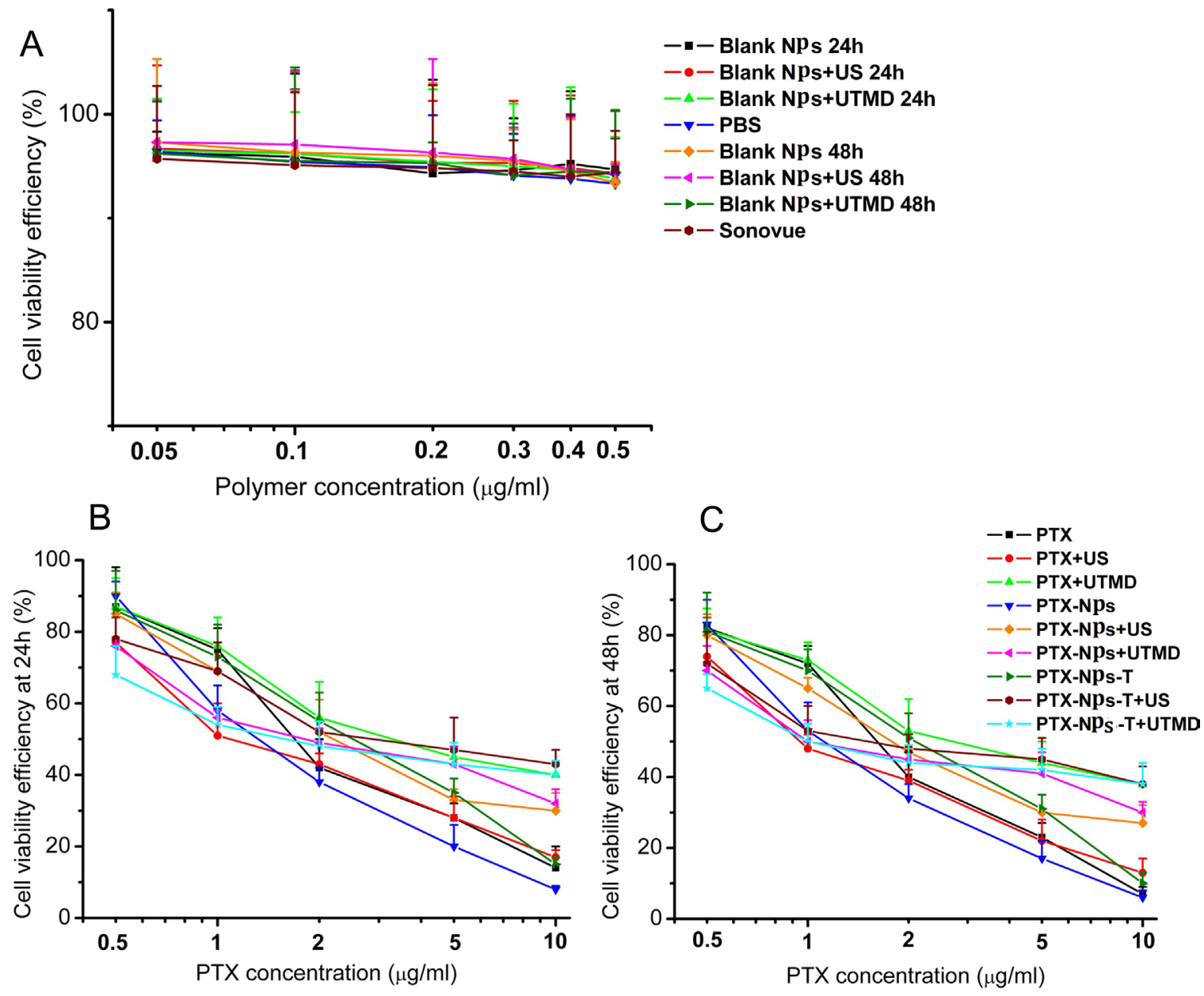

Figure 6: In vitro biocompatibility and cytotoxicity of NPs. A. Toxicity of blank NPs to AFPC-1 cells. B. Toxicity of PTX-NPs to AFPC-1cells at 24h. C. Toxicity of PTX-NPs to AFPC-1cells at 48h.

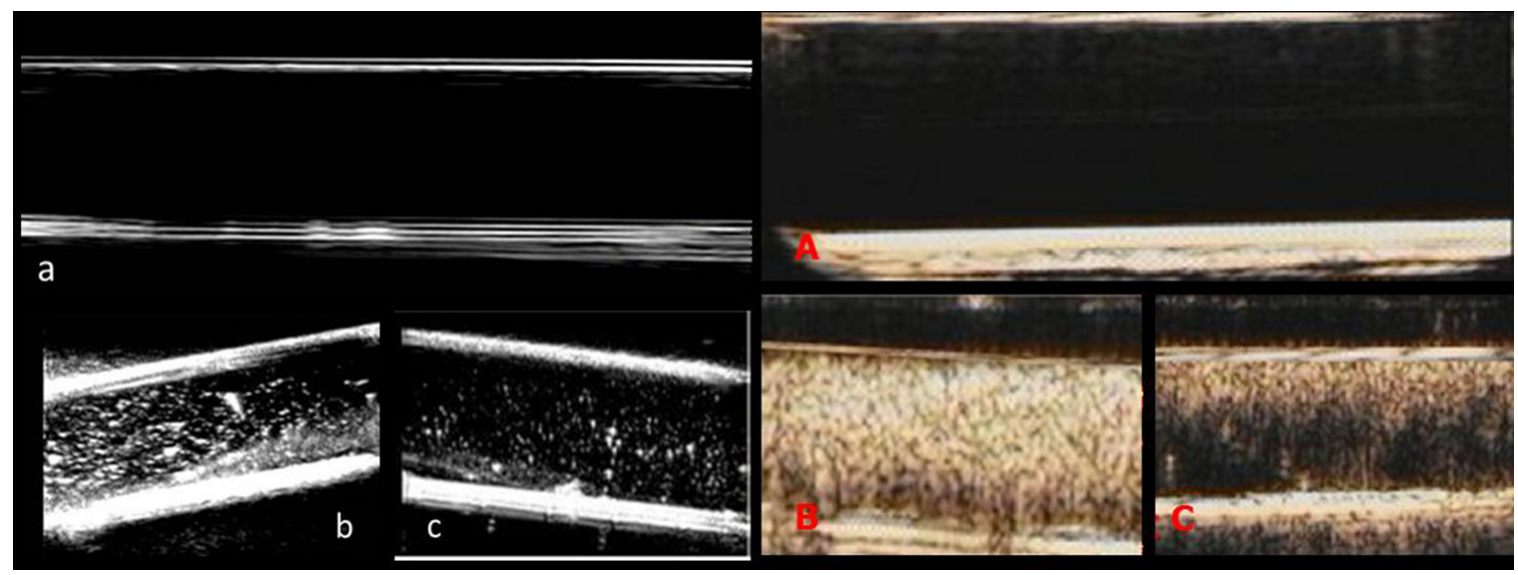

Figure 7: Two-dimensional ultrasonic imaging and ultrasound contrast enhanced imaging of UCAs in vitro. Twodimensional ultrasonic images: a. a tube filled with degassed aqueous, b. SonoVue in degassed aqueous. c. NPs in degassed aqueous. Ultrasound contrast enhanced images: A. a tube filled with degassed aqueous, B. SonoVue in degassed aqueous. C. NPs in degassed aqueous. 
Dynamic ultrasound contrast enhanced imaging process of two kinds of UCAs to the pancreas superficial implantation tumor was observed. At the $8^{\text {th }}$ second after vein bolus-injection, NPs quickly filled the tumor from the peripheral to the center with dendritic-shaped. At the $33^{\text {th }}$ second, the imaging strength reached peak and lasted for 35 seconds. The strength subsequently pulled out slowly and extinguished completely in 10 minutes. Correspondingly, SonoVue filled rapidly at the $5^{\text {th }}$ second after vein bolusinjection, reached peak at the $35^{\text {th }}$ second, then faded in 9 minutes. The SonoVue peak was higher than nano-UCA, but nanoparticles lasted longer than SonoVue. (Figure 9).
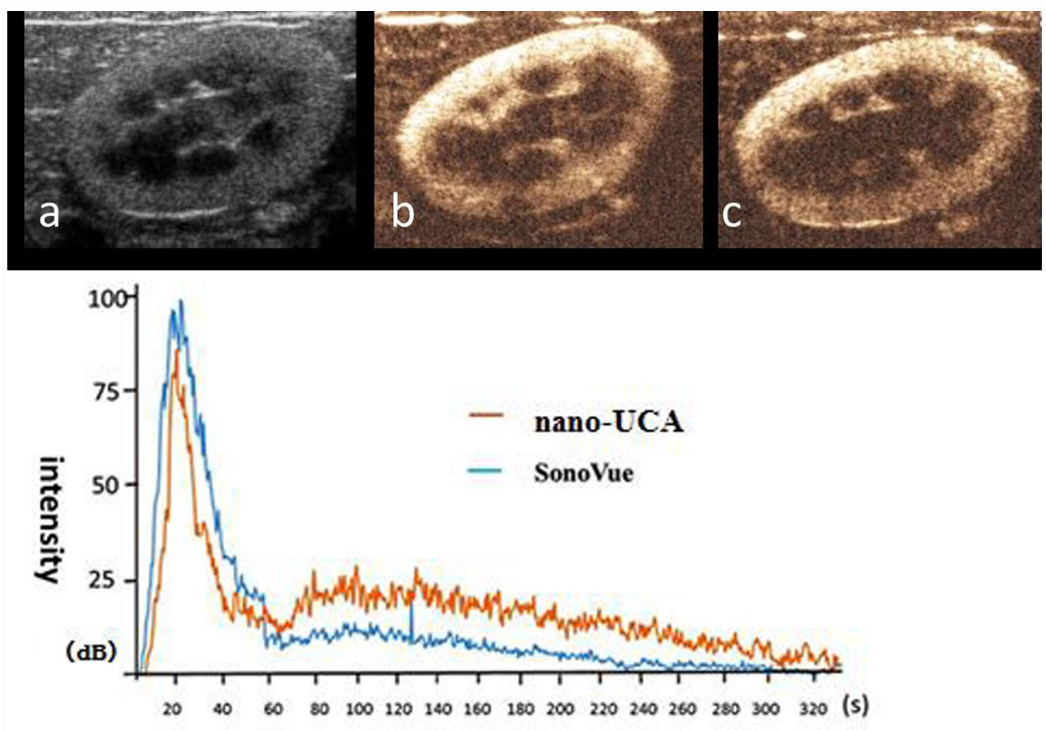

time

Figure 8: Two-dimensional ultrasonic imaging and ultrasound contrast enhanced imaging of UCAs in rabbit kidney and the time vs. intensity curve. a. two-dimensional ultrasonic images of rabbit kidney, b. SonoVue US contrast enhanced image of rabbit kidney at the filling peak c. NPs ultrasound contrast enhanced image of rabbit kidney at the filling peak.
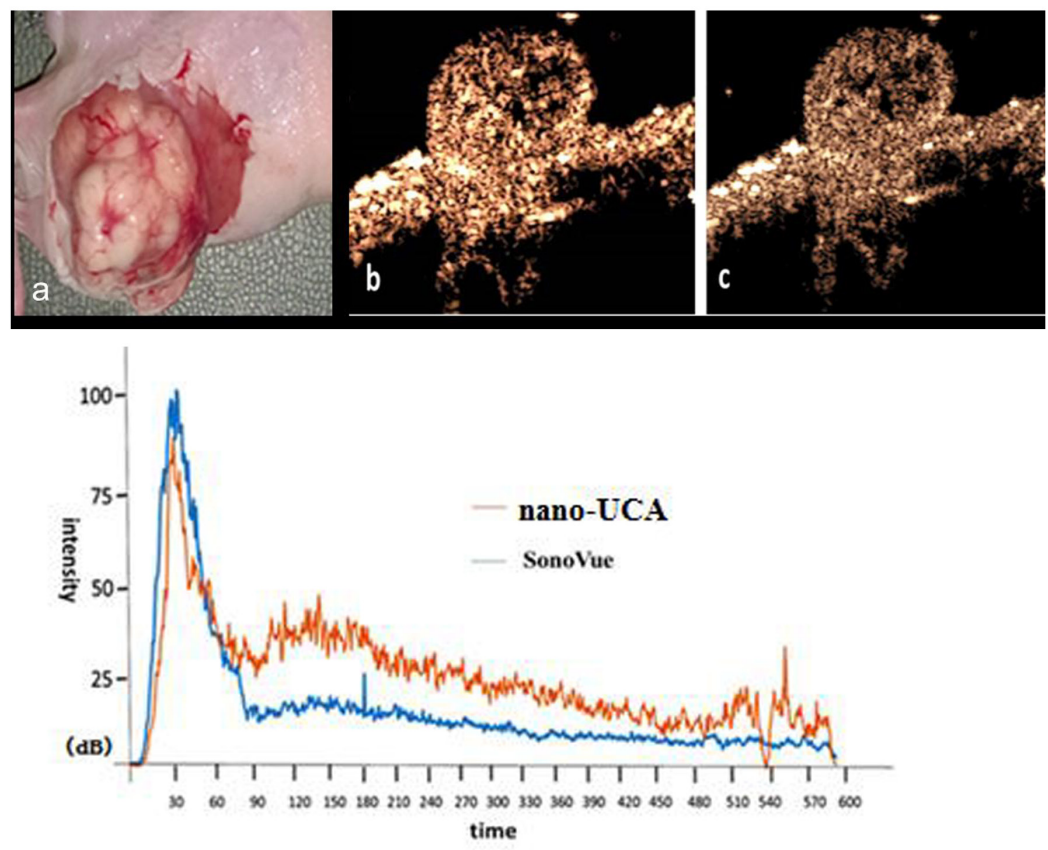

Figure 9: Ultrasound contrast enhanced imaging of two kinds of UCAs in superficial implantation tumor loaded mice and the time vs. intensity curve. a. superficial implantation tumor of pancreatic cancer in nude mouse. b. SonoVue ultrasound contrast enhanced imaging of superficial implantation tumor of pancreatic cancer in nude mouse at the filling peak. c. NPs ultrasound contrast enhanced imaging of superficial implantation tumors of pancreatic cancer in nude mouse at the filling peak time. 
Dynamic ultrasound contrast enhanced imaging process of the pancreas orthotopic implantation tumor was observed. At the 33th second after vein bolus-injection, NPs filled contemporaneously to the total tumor. At the $60^{\text {th }}$ second the imaging strength reached peak and lasted for 80 seconds. Subsequently, it pulled out slowly in $10 \mathrm{~min}$. At the $38^{\text {th }}$ second after vein bolus-injection, SonoVue filled the total tumor. At the $70^{\text {th }}$ second, the imaging strength reached peak and pulled out quickly in $10 \mathrm{~min}$. The pulling out time of NPs was longer than SonoVue. (Figure 10).

\section{DISCUSSION}

Macromolecular substances like NPs may access the cells through the mechanism of their endocytosis under the condition of no US and UTMD. Correspondingly, some possible impacting mechanisms of US or UTMD have been reported as the micro-circumflex, micro-fluid actions and so on may punch transient recoverable holes in their surfaces to motivate NPs into the cells [16-20], though the genuine mechanism remains unclear. Our research team previously proposed a novel possible mechanism, which was UTMD stimulate grid protein to promote cellular endocytosis and detailed statements were as follows: on one side, cells transportation consistently exists for a long time after the action of US or UTMD, rather than gradually weakens, for another, enhanced peak of the cells uptake was oriented at the time of the administration of UTMD 45min later, when cellular clathrin-dependent endocytosis time was overlapped [21]. The reason might be because of the suitable intensity of mPEG-PLGA. When the ultrasound is added on SonoVue, the liposome deforms instantly and strongly to good harmonic image. While the porous nanoparticle of mPEG-PLGA material may have a litter harder shell to deform weakly, possibly becoming stronger according to its accumulation intensity gradually. However, it was difficult for NPs (100 nm or so) to access the nucleus owing to the effective pore size (only $9 \mathrm{~nm}$ or so) of nucleus membrane [22]. Besides, the action power of the optimal US or UTMD was safe and impossible to affect the nucleus membranes [23, 24].

In brief, firstly, the ultrasound contrast enhanced images were good enough to show lesions in terms of this kind of novel targeted NPs. The hollow holes in lyophilized multi-porous targeted NPs may be so small that stronger ultrasonic reflection and scattering signals would require a higher concentration of the targeted NPs aqueous for US contrast imaging [25, 26], compared with SonoVue. Though no obvious difference was detected at the beginning or peak time of the two kinds of UCAs, targeted NPs faded more slowly in comparison with SonoVue. The longer clear-time of targeted NPs lasted for 10 min, which demonstrated that in one respect, it was very possible for them to enter more microvasculars than SonoVue. For another, targeted NPs could partly penetrate
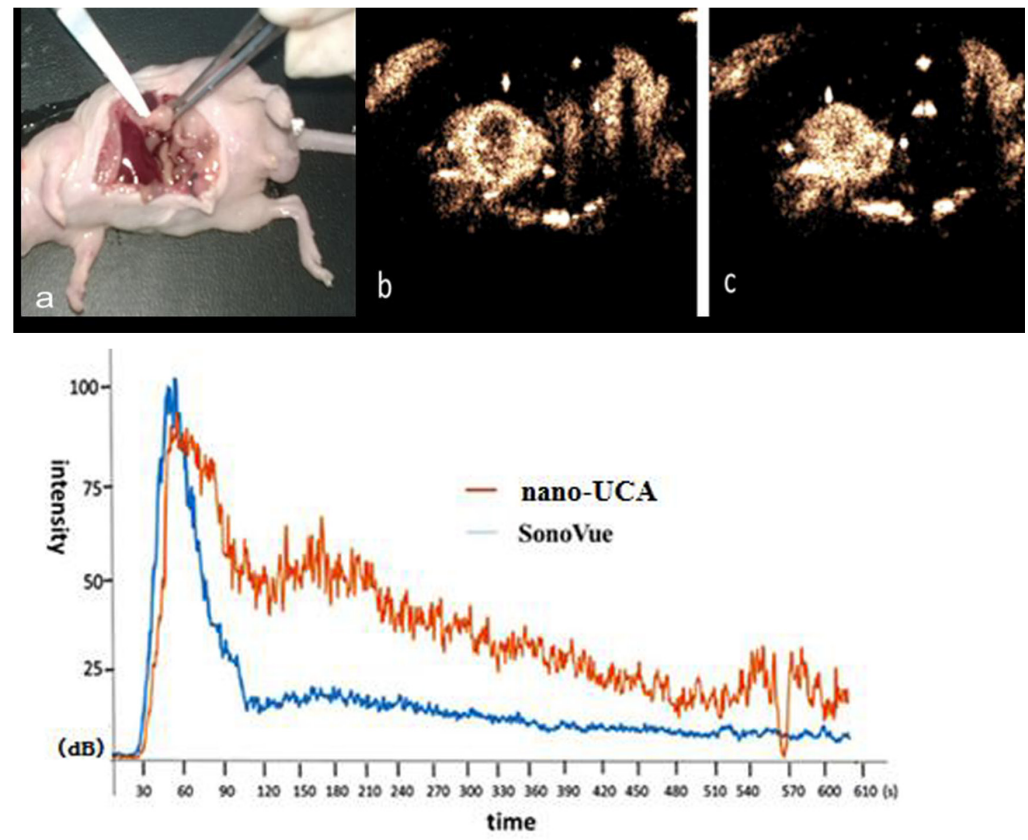

Figure 10: Ultrasound contrast enhanced imaging of UCAs in orthotopic implantation tumor of pancreatic cancer in nude mice and the time vs. intensity curve. a. Orthotopic implantation tumor of pancreatic cancer in nude mouse, b. SonoVue ultrasound contrast enhanced image of orthotopic implantation tumor of pancreatic cancer in nude mouse at the filling peak time, c. NPs ultrasound contrast enhanced image of orthotopic implantation tumor of pancreatic cancer in nude mouse at the filling peak time. 
into organization gaps and bind to the surface of tumor cells to form aggregation effect.

Conventional UCAs such as lipid-shelled SonoVue which was filled with sulfur hexafluoride gas have been widely used in clinic work. These types of UCAs have the function of excellent contrast enhanced imaging. However, they cannot give some corresponding therapy in the meanwhile. The double-targeted NPs could not only supply contrast enhanced imaging but also deliver drug into the tumor cells. It was a promising preparation in clinic. There are still some efforts should be done in our future work. The particle size should be reduced to improve the imaging efficiency. And the drug load ratio should be further improved to enhance tumor inhibition effect.

\section{MATERIALS AND METHODS}

\section{Materials}

The 1-(3-Dimethylaminopropyl)-3-ethylcarb odiimide hydrochloride (EDC), N-hydroxysuccinimide (NHS), rhodamine $(\mathrm{Rh})$ and fluorescein isothiocyanate isomer (FITC) were purchased from Sigma Aldrich Company (Shanghai, China). The mPEG-PLGA (mPEG 5000, GA: LA=8:2) was donated by the Shanghai Cancer Institute (Shanghai, China). Dialysis bags were purchased from Lv Niao technology Co. Ltd (Shanghai, China). Paclitaxel was from Jiangsu yew pharmaceutical Co. Ltd (Jiangsu, China). Pluronic-F68 (F68) was obtained from BASF (China) Co. Ltd. (Shanghai, China). CCK-8 kit was purchased from Dong Ren chemistry Co. Ltd (Shanghai, China). IMDM medium and 10\% fetal bovine serum, penicillin, streptomycin were purchased from Gibco (New York, USA). CA19-9 antibody, CEA antibody and 4, 6-diamino-2-phenyl indole (DAPI) were purchased from Qian Chen Biological Technology Co.Ltd (Shanghai, China). Other reagents were from Sinopharm Chemical Reagent Co.Ltd (Shanghai, China).

The CFAPC-1 pancreatic cancer cells were purchased from Cell Bank, Shanghai Institutes for Biological Sciences, Chinese Academy of Sciences (Shanghai, China). SonoVue was from Bracco Imaging. BV (Milan, Italy). The animals were supplied by the First People' Hospital Affiliated to Shanghai Jiao tong University (Shanghai, China). All animal procedures were performed according to the research protocol approved by the Animal Care and Use Committee at the First People' Hospital Affiliated to Shanghai Jiao tong University.

\section{Fabrication of PTX-mPEG-PLGA NPs}

Firstly, 3.5mg PTX and 125mg mPEG-PLGA were dissolved into $5 \mathrm{ml}$ dichloromethane solution. Then $200 \mathrm{uL} 0.5 \mathrm{mg} / \mathrm{ml} \mathrm{F68} \mathrm{solution} \mathrm{was} \mathrm{added} \mathrm{into} \mathrm{the}$ dichloromethane solution and emulsified for $1.5 \mathrm{~min}$ by the work-frequency (one time per 2 second). Subsequently $50 \mathrm{ml} \mathrm{F68} \mathrm{solution} \mathrm{was} \mathrm{added} \mathrm{and} \mathrm{emulsified} \mathrm{for} 1 \mathrm{~min}$ by the same work-frequency mentioned. The dichloromethane was removed by stirred at room temperature. The NPs was lyophilized to remove the inner water phase.

\section{Fabrication of the double-targeted PTX-NPs modified by anti-CEA antibody and anti-CA19-9 antibody}

50mg PTX-mPEG-PLGA was dispersed into $50 \mathrm{ml}$ water and $1 \mathrm{mg}$ CA19-9 and 1mg CEA was added. Then, $1 \mathrm{mg}$ EDC and $1 \mathrm{mg}$ NHS were dissolved into the solution and stirred for an hour at room temperature. The solution was dialyzed (molecular weight cut off $(\mathrm{MwCO}=3500)$ for an hour to remove EDC and NHS. The NPs solution was then separated through a sephadex G50 column to remove the unconjugated antibodies.

\section{Characterization of the double-targeted PTX NPs}

The size distribution and zeta potential of the double-targeted NPs were determined using a particle size/zeta potential analyzer from particle sizing system, Inc. (Florida, USA). The morphology characteristics of the double-targeted PTX-mPEG-PLGA NPs were observed using transmission electronmicroscopy (TEM) from Hitachi, Ltd. (Japan). The infrared spectrum of doubletargeted PTX-mPEG-PLGA NPs were detected by Vertex 70FT-IR Spectrometers (Germany).

We observed the double-targeted NPs compared to SonoVue under optical microscope. 20ul NPs degassed aqueous (mPEG-PLGA concentration: $17 \mathrm{mg} / \mathrm{ml}$ ) and 20ul SonoVue degassed aqueous (concentration: $17 \mathrm{mg}$ / $\mathrm{ml}$ ) were respectively observed with optical microscope.

The drug entrapment efficiency of PTX was determined by the high performance liquid chromatograph (HPLC). 200ul NPs water solution was added into $2 \mathrm{ml}$ volumetric flask and dissolved with acetonitrile. The NPs were dissolved by ultrasonic and filtered with $0.45 \mu \mathrm{m}$ microfiltration membrane and detected by HPLC analyzer. The detection parameters were as follows: Hypersil BDS C18 chromatographic column (Dalian elite Co. $150 \times 4.6 \mathrm{~mm}, 5 \mu \mathrm{m})$. Acetonitrile- $10 \mathrm{mmol} / \mathrm{L} \mathrm{NH}_{4} \mathrm{Ac}$ solution ( $\mathrm{pH}$ 5.0) 53:47 was as the mobile phase. The column temperature was $30^{\circ} \mathrm{C}$. The flow rate was $1 \mathrm{ml} /$ $\min$. The detection wave was $227 \mathrm{~nm}$.

The entrapment efficiency was defined by the ratio of the amount of PTX embedded in the double-targeted PTX-mPEG-PLGA NPs to the total amount of PTX incipiently used. The loading drug efficiency was defined by the ratio of the weight of PTX embedded in the doubletargeted PTX-mPEG-PLGA NPs to the weight of doubletargeted PTX-mPEG-PLGA NPs. 


\section{Drug release of PTX from the double-targeted NPs}

A dialysis-bag $(\mathrm{MWCO}=3500)$, in which $1 \mathrm{ml}$ PTX-mPEG-PLGA NPs aqueous was sealed, was immersed into $19 \mathrm{ml}$ phosphate buffered saline (PBS) solution containing $1 \mathrm{moL} / \mathrm{L}$ sodium salicylate $(\mathrm{pH}=5.0$, $6.5,7.4$ ) and shaked at $37^{\circ} \mathrm{C}$. At predetermined time, $200 \mu \mathrm{L}$ sample of the dialysis bag were taken out and fresh medium of the same volume was added. PTX dimethylsulfoxide (DMSO) solution was used as control. PTX concentrations of samples were determined by HPLC and release quantity of PTX was calculated to draw the cumulative release-time curves. PTX release efficiency was determined by the ratio of the PTX amount released into solution to the total amount of PTX in the double-targeted NPs.

\section{US and UTMD condition optimization}

Human Pancreatic cancer CFAPC-1 cells were incubated in Iscove's Modified Dulbecco's Medium (IMDM) with $10 \%$ fetal bovine serum (FBS), penicillin and streptomycin $(100 \mu \mathrm{g} / \mathrm{ml})$ at $37^{\circ} \mathrm{C}$ in a humidified condition with $5 \% \mathrm{CO}_{2}$.

A therapeutic US machine (Physiomed, Erlangen, Germany) was used, on which some conditions were fixed as followed: the frequency of the probe was $1 \mathrm{MHz}$, duty cycle:1:5. According to US power, US irradiation time, SonoVue volume ratio, diverse experiment conditions were designed into 20 groups (Chart 1). Encapsulating RhB double-targeted NPs were added into CFAPC-1 cells and incubated for $2 \mathrm{hr}$ under the 20 setting conditions respectively. Then the cells were trypsinized and collected to be analyzed by flowcytometry (FCM).

\section{Cell uptake observed by confocal laser scanning microscope (CLSM)}

CFAPC-1 cells were incubated in confocal dishs for $2 \mathrm{hrs}$ with RbB-mPEG-PLGA NPs and RbB-doubletargeted NPs respectively. The US or UTMD condition was optimized above. The cells were fixed and dyed before viewed through CLSM.

\section{Cyto-compatibility and antitumor effect of double-targeted NPs}

The cellular cytotoxicity of the NPs was determined by MTT assay. CFAPC- 1 cells $\left(1 \times 10^{5} /\right.$ well $)$ were cultured in 96-well plates for $24 \mathrm{~h}$. Then the cells were treated with different conditions and incubated for 24 and $48 \mathrm{~h}$ at $37^{\circ} \mathrm{C}$. The fixed probe frequency was $1 \mathrm{MHz}$, duty cycle was $20 \%$. The optimal US (power, $1 \mathrm{~W} / \mathrm{cm} 2$; exposure time,
$60 \mathrm{sec}$ ) or UTMD conditions (power, $1 \mathrm{~W} / \mathrm{cm} 2$; exposure time, $60 \mathrm{sec}$; SonoVue volume ratio, 2:5) were used. Subsequently, the medium in the wells were removed and $0.2 \mathrm{ml}$ fresh medium of MTT $(0.5 \mathrm{mg} / \mathrm{ml})$ was added to every well and incubated for $4 \mathrm{~h}$ at $37^{\circ} \mathrm{C}$. The culture medium was then removed from the wells and replaced with $0.2 \mathrm{ml}$ dimethyl sulfoxide. Following agitation of the 96-well plates for 15-20 min, the absorbance was measured at a wavelength of $490 \mathrm{~nm}$ using a Model 680 Microplate Reader from Bio-Rad Laboratories (Hercules, CA, USA).

\section{Respectively two dimensional ultrasound and ultrasound contrast enhanced imaging of NPs in vitro}

Philips IE33 was used and the probe was L11-3. Firstly, NPs powder were respectively put into Eppendorf tube (concentration: $17 \mathrm{mg} / \mathrm{ml}$ ) filled with degassed water, sealed and vibrated fully. The outer surfaces of the tube were covered with ultrasound coupling agent to keep no air between the tubes and the transducer. Ultrasound contrast enhanced images was taken immediately and SonoVue was observed as comparison.

\section{Respectively two dimensional ultrasound and ultrasound contrast enhanced imaging of NPs and SonoVue in vivo}

The CFAPC-1 orthotopic tumor was set up by injecting $20 \mu \mathrm{l}$ CFAPC-1 cells spension $\left(5 \times 10^{7} / \mathrm{ml}\right)$ into the pancreas of $\mathrm{BALB} / \mathrm{c}$ nude mouse.

Siemens Sequaio512 and LOGIQ E9 were used and the corresponding probes were respectively $15 \mathrm{~L} 8 \mathrm{~W}-\mathrm{S}$ and ML6-14. SonoVue degassed aqueous $(0.2 \mathrm{ml}$, concentration: $17 \mathrm{mg} / \mathrm{ml}$ ) and NPs degassed aqueous $(0.2 \mathrm{ml}$, concentration: $17 \mathrm{mg} / \mathrm{ml})$ were quickly injected into rabbit ear veins respectively, in the meanwhile, ultrasound contrast imagines of the rabbit right kidney were real-time observed and recorded. In the same way, $0.1 \mathrm{ml} \mathrm{NPs}$ and $0.1 \mathrm{ml}$ SonoVue were quickly injected into tail vein of orthotropic pancreas tumors loaded nude mice respectively. At the same time, ultrasound contrast enhanced imaging of superficial was also real-time observed and recorded.

\section{Statistics}

Measurement data were displayed with $\overline{\mathrm{x}} \pm \mathrm{sd}$. Statistical tests were processed using the Student's $t$-test, and the statistical difference for significance between the experimental and control groups was analyzed using SPSS19.0 software. The statistical significance was determined at $p$ values $<0.05$. 


\begin{tabular}{lccc}
\hline Group & US power & US irradiation time & SonoVue volume ratio \\
\hline 1 & $0.8 \mathrm{w}$ & $40 \mathrm{~s}$ & $20 \%$ \\
2 & $0.8 \mathrm{w}$ & $60 \mathrm{~s}$ & $20 \%$ \\
3 & $0.8 \mathrm{w}$ & $80 \mathrm{~s}$ & $20 \%$ \\
4 & $1.0 \mathrm{w}$ & $40 \mathrm{~s}$ & $20 \%$ \\
5 & $1.0 \mathrm{w}$ & $60 \mathrm{~s}$ & $20 \%$ \\
6 & $1.0 \mathrm{w}$ & $80 \mathrm{~s}$ & $20 \%$ \\
7 & $1.2 \mathrm{w}$ & $40 \mathrm{~s}$ & $20 \%$ \\
8 & $1.2 \mathrm{w}$ & $60 \mathrm{~s}$ & $20 \%$ \\
9 & $1.2 \mathrm{w}$ & $80 \mathrm{~s}$ & $20 \%$ \\
10 & No US & & $40 \%$ \\
11 & $0.8 \mathrm{w}$ & $40 \mathrm{~s}$ & $40 \%$ \\
12 & $0.8 \mathrm{w}$ & $60 \mathrm{~s}$ & $40 \%$ \\
13 & $0.8 \mathrm{w}$ & $80 \mathrm{~s}$ & $40 \%$ \\
14 & $1.0 \mathrm{w}$ & $40 \mathrm{~s}$ & $40 \%$ \\
15 & $1.0 \mathrm{w}$ & $60 \mathrm{~s}$ & $40 \%$ \\
16 & $1.0 \mathrm{w}$ & $80 \mathrm{~s}$ & $40 \%$ \\
17 & $1.2 \mathrm{w}$ & $40 \mathrm{~s}$ & $40 \%$ \\
18 & $1.2 \mathrm{w}$ & $60 \mathrm{~s}$ & $40 \%$ \\
19 & $1.2 \mathrm{w}$ & $80 \mathrm{~s}$ & \\
20 & & Rh & solution, no US \\
\hline
\end{tabular}

\section{ACKNOWLEDGMENTS}

The current study was supported by the Department of Ultrasound, Shanghai First People's Hospital Affiliated to Shanghai Jiao tong University School of Medicine (Shanghai, China) and the National Natural Science Foundation of China (81271596, 81171352, 81501483 and 81502692).

\section{CONFLICTS OF INTEREST}

All the authors of this paper declare that they have no conflicts of interest.

\section{REFERENCES}

1. Chen M, Cooper HM, Zhou JZ, Bartlett PF, Xu ZP. Reduction in the size of layered double hydroxide nanoparticles enhances the efficiency of siRNA delivery. $\mathrm{J}$ Colloid Interface Sci. 2013; 390: 275-281.

2. Liang Y, Wang W, Fang C, Raj SS, Hu WM, Li QW, Zhou ZW. Clinical significance and diagnostic value of serum CEA, CA19-9 and CA72-4 in patients with gastric cancer. Oncotarget. 2016; 7: 49565-49573. doi: 10.18632/ oncotarget.10391.

3. Yuan C, Yang K, Tang H, Chen D. Diagnostic values of serum tumor markers Cyfra21-1, SCCAg, ferritin, CEA, CA19-9, and AFP in oral/oropharyngeal squamous cell carcinoma. OncoTargets Ther. 2016 Jun 3; 9:3381-6. doi: 10.2147/OTT.S105672. eCollection 2016.

4. Miller DL, Gies RA. The interaction of ultrasonic heating and cavitation in vascular bioeffects on mouse intestine. Ultrasound Med Biol. 1998; 24: 123-128.

5. Sonoda S, Tachibana K, Uchino E, Okubo A, Yamamoto M, Sakoda K, Hisatomi T, Sonoda KH, Negishi Y, Izumi Y, Takao S, Sakamoto T. Gene transfer to corneal epithelium and keratocytes mediated by ultrasound with microbubbles. Invest Ophthalmol Vis Sci. 2006; 47: 558-564.

6. $\mathrm{Wu}$ Y, Du LF, Chen YD. SonoVue and ultrasound-mediated pEGFP-N1 transfection to mouse cornea in an in vivo study. Chin J Ultrasonogr. 2008; 17: 350-353.

7. Du J, Sun Y, Shi QS, Liu PF, Zhu MJ, Wang CH, Du LF, Duan YR. Biodegradable nanoparticles of mPEG-PLGAPLL triblock copolymers as novel non-viral vectors for 
improving siRNA delivery and gene silencing. Int J Mol Sci. 2012; 13: 516-533.

8. Chumakova OV, Liopo AV, Andreev VG, Cicenaite I, Evers BM, Chakrabarty S, Pappas TC, Esenaliev RO. Composition of PLGA and PEI/DNA nanoparticles improves ultrasound-mediated gene delivery in solid tumors in vivo. Cancer Lett. 2008; 261: 215-225.

9. Hosseinkhani $\mathrm{H}$, Tabata $\mathrm{Y}$. Ultrasound enhances in vivo tumor expression of plasmid DNA by PEG-introduced cationized dextran. J Control Release. 2005; 108: 540-556.

10. Rapoport N, Gao Z, Kennedy A. Multifunctional nanoparticles for combining ultrasonic tumor imaging and targeted chemotherapy. J Natl Cancer Inst. 2007; 99: 1095-1106.

11. Du J, Sun Y, Shi QS, Liu PF, Zhu MJ, Wang CH, Du LF, Duan YR. Biodegradable nanoparticles of mPEG-PLGAPLL triblock copolymers as novel non-viral vectors for improving siRNA delivery and gene silencing. Int J Mol Sci. 2012, 13: 516-533.

12. Chumakova OV, Liopo AV, Andreev VG, Cicenaite I, Evers BM, Chakrabarty S, Pappas TC, Esenaliev RO. Composition of PLGA and PEI/DNA nanoparticles improves ultrasound-mediated gene delivery in solid tumors in vivo. Cancer Lett. 2008; 261: 215-225.

13. Hauff P, Seemann S, Reszka R, Schultze-Mosgau M, Reinhardt M, Buzasi T, Plath T, Rosewicz S, Schirner M. Evaluation of gas-filled microparticles and sonoporation as gene delivery system: feasibility study in rodent tumor models. Radiology. 2005; 236: 572-578.

14. Torchilin VP. Passive and active drug targeting: drug delivery to tumors as an example. Handb Exp Pharmacol. 2010; 197: 3-53.

15. Ke H, Wang J, Dai Z, Jin Y, Qu E, Xing Z, Guo C, Yue X, Liu J. Gold-nanoshelled microcapsules: a theranostic agent for ultrasound contrast imaging and photothermal therapy. Angew Chem Int Ed Engl. 2011; 50: 3017-3021.

16. Hughes GA. Nanostructure-mediated drug delivery. Nanomedicine. 2005; 1: 22-30.

17. Lanza GM, Trousil RL, Wallace KD, Rose JH, Hall CS, Scott MJ, Miller JG, Eisenberg PR, Gaffney PJ, Wickline $\mathrm{SA}$. In vitro characterization of a novel, tissue-targeted ultrasonic contrast system with acoustic microscopy. J Acoust Soc Am. 1998; 104: 3665-3672.

18. Tachibana K, Uchida T, Ogawa K, Yamashita N, Tamura K. Induction of cell-membrane porosity by ultrasound. Lancet. 1999; 353: 1409.

19. Van Wamel A, Kooiman K, Harteveld M, Emmer M, ten Cate FJ, Versluis M, de Jong N. Vibrating microbubbles poking individual cells: drug transfer into cells via sonoporation. J Control Release. 2006; 112: 149-155.

20. Juffermans LJ, Dijkmans PA, Musters RJ, Visser CA, Kamp O. Transient permeabilization of cell membranes by ultrasound-exposed microbubbles is related to formation of hydrogen peroxide. Am J Physiol Heart Circ Physiol. 2006; 291: H1595-H1601.

21. Miller DL, Gies RA. The interaction of ultrasonic heating and cavitation in vascular bioeffects on mouse intestine. Ultrasound Med Biol. 1998; 24: 123-128.

22. Schlicher RK, Radhakrishna H, Tolentino TP, Apkarian RP, Zarnitsyn V, Prausnitz MR. Mechanism of intracellular delivery by acoustic cavitation. Ultrasound Med Biol. 2006; 32: 915-924.

23. Jin LF, Li F, Wang HP. Ultrasound targeted microbubble destruction stimulates cellular endocytosis in facilitating adeno-associated virus delivery. Int J Mol Sci. 2013; 14: 9737-9750.

24. Samudram A, Mangalassery BM, Kowshik M, Patincharath N, Varier GK. Passive permeability and effective pore size of HeLa cell nuclear membranes. Cell Biol Int. 2016; Jun 23. doi: 10.1002/cbin.10640. [Epub ahead of print]

25. Zhang Y, Ye C, Wang G, Gao Y, Tan K, Zhuo Z, Liu Z, Xia H, Yang D, Li P. Kidney-targeted transplantation of mesenchymal stem cells by ultrasound targeted microbubble destruction promotes kidney repair in diabetic nephropathy rats. BioMed Res Int. 2013; 2013: 526367.

26. Li P, Gao Y, Zhang J, Liu Z, Tan K, Hua X, Gong J. Renal interstitial permeability changes induced by microbubble enhanced diagnostic ultrasound. J Drug Target. 2013; 21: 507-514. 